03,05

\title{
Влияние термообработки на дисперсию магнитной анизотропии нановключений MnSb, внедренных в тонкие пленки GaMnSb
}

\author{
(c) А.И. Дмитриев ${ }^{1,2}$, А.В. Кочура ${ }^{3}$, А.П. Кузьменко ${ }^{3}$, Л.С. Паршина ${ }^{4}$, О.А. Новодворский ${ }^{4}$, \\ О.Д. Храмова ${ }^{4}$, Е.П. Кочура ${ }^{3}$, А.Л. Васильев ${ }^{5}$, Б.А. Аронзон ${ }^{5,6}$ \\ ${ }^{1}$ Институт проблем химической ффизики РАН, \\ Черноголовка, Россия \\ ${ }^{2}$ Российский университет транспорта, \\ Москва, Россия \\ ${ }^{3}$ Юго-Западный государственный университет, \\ Курск, Россия \\ ${ }^{4}$ Институт проблем лазерных и информационных технологий РАН, \\ фрилиал ФНИЦ „Кристаллография и фотоника“ РАН, \\ Шатура, Россия \\ ${ }^{5}$ Национальный исследовательский центр „Курчатовский институт“, \\ Москва, Россия \\ ${ }^{6}$ Физический институт им. П.Н.Лебедева РАН, \\ Москва, Россия \\ E-mail: aid@icp.ac.ru \\ (Поступила в Редакцию 8 ноября 2018 г. \\ В окончательной редакции 8 ноября 2018 г. \\ Принята к публикации 8 ноября 2018 г.)
}

В тонких пленках $\mathrm{GaMnSb}$ с нановключениями $\mathrm{MnSb}$, полученных методом импульсного лазерного осаждения, наблюдается температурноконтролируемое увеличение магнитной анизотропии и ее дисперсии. Данные просвечивающей электронной микроскопии указывают на то, что в образцах происходит переход кристаллической структуры магнитных нановключений $\mathrm{MnSb}$ из гексагональной (п. г. $\left.P 6_{3} / m m c\right)$ в кубическую (п. г. $F-43 m)$. Анализ температурных зависимостей магнитного момента $m(T)$, измеренных с помощью СКВИД-магнитометра, для неотожженных и отожженных образцов, охлажденных в нулевом магнитном поле и магнитном поле напряженностью $10 \mathrm{kOe}$, указывает на то, что этот механизм не является единственным. В неотожженных образцах распределение магнитной анизотропии нановключений $\mathrm{MnSb}$, определенное из зависимостей $m(T)$, является унимодальным. В отожженных образцах эта же зависимость становится мультимодальной. Это означает, что в образцах при отжиге протекают несколько термоактивированных процессов, приводящих к тому, что в отожженных тонких пленках присутствуют несколько „популяций“ нановключений. Вклад в увеличение магнитной анизотропии при отжиге могут давать как структурный фазовый переход, так и рассогласование кристаллических решеток между $\mathrm{MnSb}$ и GaSb, увеличение среднего объема нановключений $\mathrm{MnSb}$, а также изменение их стехиометрии.

Работа выполнена по теме государственного задания 0089-2019-0011 с использованием оборудования Аналитического центра коллективного пользования ИПХФ РАН, а также при поддержке Министерства образования и науки РФ (№ 16.2814.2017/ПЧ) и РФФИ (№ 17-02-00262, 15-07-03580). В части осаждения тонких пленок $\mathrm{GaMnSb}$ работа выполнена при поддержке Министерства науки и высшего образования в рамках государственного задания ФНИЦ „Кристаллография и фотоника“ РАН (соглашение № 007-ГЗ/Ч3363/26).

DOI: 10.21883/FTT.2019.04.47407.310

\section{1. Введение}

Наличие у электрона электрического заряда и взаимодействие его с электромагнитным полем является физической основой электроники. Электроны обладают не только зарядом, но и собственным магнитным моментом - спином. Попытки использования спина в новых устройствах хранения, обработки и передачи информации с расширенной функциональностью привело к появлению нового направления в науке и технике - спинтронике. Одним из ключевых направлений спинтроники, да и физики твердого тела в целом, является создание и управление спиновой поляризацией носителей заряда в полупроводниках. Ранее в качестве основных методов для этого использовались оптическая поляризация [1] и инжекция в полупроводники поляризованных носителей из ферромагнетиков [2]. В настоящее время надежно установлено, что в самых различных полупроводниках, сильно легированных переходными металлами (1-10at.\%), при низких температурах наблюдается дальний магнитный порядок [3-8]. Поэтому разбавленные магнитные полупроводники (РМП) эффективная среда для создания „собственной“с спиновой поляризации носителей заряда. Однако величина косвенного обмена, поддерживающего спин-поляризованное состояние настолько мала, что соответствующие темпе- 
ратуры Кюри $\left(T_{C}\right)$ для РМП на основе традиционных материалов электроники значительно ниже комнатной (обычно $T C<200 \mathrm{~K}$ ). Причина заключается в плохой растворимости примеси переходных металлов в полупроводниковой матрице и, как следствие, образование различных нановключений вторичной фазы [9-16]. Присутствие таких включений, зачастую ферромагнитных при комнатной температуре, обычно считалось нежелательным в практических приложениях, т.к. их образование приводило к существенному снижению подвижности носителей заряда и обеднению подсистемы диспергированных ионов переходных металлов и, как следствие, к понижению температуры магнитного упорядочения в ней. Однако недавно появились отдельные свидетельства в пользу того, что ферромагнитные нановключения могут формировать необычные свойства разбавленных магнитных полупроводников, требуемые спинтроникой. В качестве примеров можно указать: магнитный круговой дихроизм и фарадеевское вращение в пленках GaMnAs с включениями MnAs, полученных методом молекулярно-лучевой эпитаксии $[17,18]$; положительное магнетосопротивление в пленках $\mathrm{GaMnAs}$ c включениями MnAs [19] и анизотропное микроволновое магнетосопротивление в пленках GeMn с включениями $\mathrm{MnGe}[20,21]$, полученных методом ионной имплантации; генерация спинового тока в тонких пленках GaMnAs за счет спонтанного перемагничивания включений MnAs [22] и т. д.

В настоящей работе исследованы тонкие пленки $\mathrm{GaMnSb}$ с нановключениями $\mathrm{MnSb}$, полученные методом импульсного лазерного осаждения. Ранее тонкие пленки $\mathrm{GaMnSb}$ с нановключениями $\mathrm{MnSb}$ привлекли внимание исследователей из-за наличия в них положительного эффекта Холла с гистерезисом вплоть до комнатных температур [23]. Аномальный эффект Холла является свидетельством спиновой поляризации носителей заряда, зависящей от намагниченности образца. К настоящему моменту эти образцы довольно хорошо исследованы. В работах [24,25] определены основные магнитные характеристики (коэрцитивная сила, температура блокировки, константа магнитной анизотропии и т.д.), исследовано микроволновое магнетосопротивление и зависимость намагниченности от концентрации носителей заряда. В работе [26] изучено спонтанное перемагничивание нановключений $\mathrm{MnSb}$, внедренных в тонкие пленки, что приблизило понимание механизмов возникновения электродвижущей силы в „спиновых батарейках“. В работе [27] установлена взаимосвязь между спонтанным и вынужденным перемагничиванием тонких пленок. В работе [28] определены условия и механизмы контролируемого изменения магнитой анизотропии пленок $\mathrm{GaMnSb}$ посредством термообработки. Было установлено, что термообработка пленок $\mathrm{GaMnSb}$ приводит к заметному увеличению характеристик нановключений $\mathrm{MnSb}$, определяющихся магнитной анизотропией: температуры блокировки от 95 до $390 \mathrm{~K}$ и поля магнитной анизотропии от 330 Ое до 630 Ое. Данные просвечивающей электронной микроскопии показали, что изменение магнитной анизотропии образцов в результате термообработки обусловлено переходом кристаллической структуры магнитных нановключений $\mathrm{MnSb}$ из гексагональной (п. г. $\left.P 6_{3} / m m c\right)$ в кубическую (п. г. $\left.F-43 m\right)$ [11]. При этом нужно отметить, что магнитные свойства (форма петель магнитного гистерезиса, вид температурной зависимости намагниченности и др.) подобных композитных образцов определяется не столько величиной магнитной анизотропии, сколько ее дисперсией. Некоторые экспериментальные данные о влиянии термообработки на магнитную анизотропию тонких пленок $\mathrm{GaMnSb}$ получены и опубликованы в работе [28]. Однако зависимость дисперсии их магнитной анизотропии от условий синтеза изучена не была. Поэтому целью настоящей работы является установление влияния термообработки на дисперсию магнитной анизотропии нановключений $\mathrm{MnSb}$, внедренных в тонкие пленки GaMnSb.

\section{2. Методика эксперимента}

Пленки $\mathrm{GaMnSb}$ толщиной $\sim 100 \mathrm{~nm}$ и площадью $\sim 1 \mathrm{~cm}^{2}$, были получены из мишеней сплава $\mathrm{GaSb}-\mathrm{MnSb}$ эвтектического состава (41 mol.\% MnSb и $59 \mathrm{~mol} \% \mathrm{GaSb})$, методом импульсного лазерного осаждения в режиме сепарации капель в условиях высокого вакуума $\left(10^{-6}\right.$ Torr $)$ при температуре подложки $\left(T_{s}\right)$ от $50^{\circ} \mathrm{C}$ до $300^{\circ} \mathrm{C}$. В качестве подложек использовался монокристаллический сапфир ориентации (0001). После напыления часть образцов была подвергнута отжигу в вакууме при температуре $350^{\circ} \mathrm{C}$ в течение $30 \mathrm{~min}$. Подробнее методика синтеза пленок описана ранее $[24,25,29,30]$. Для исследований были выбраны образцы, полученные при $T_{s}=100^{\circ} \mathrm{C}$. Структура и состав пленок контролировались сканирующим и просвечивающим электронными микроскопами (ПЭМ).

Структура и элементный состав на поверхности пленок изучались с помощью сканирующего электронного микроскопа JSM-6610LV (Jeol) с приставкой для энергодисперсионной рентгеновской спектроскопии (ЭДРС) X-MaxN (Oxford Instruments).

Дополнительно свойства поверхности исследовались с помощью сканирующего зондового микроскопа AIST-NT SmartSPM 1000, оснащенного нагревателем образцов, с применением методик атомносиловой (ACM) и магнитосиловой (МСМ) микроскопии.

Для исследования кристаллической структуры образцов с помощью ПЭМ стандартными методами были приготовлены поперечные срезы структуры отожженных и неотожженных пленок GaMnSb. Для этого пленочные образцы были разрезаны алмазной пилой на полоски шириной около $1 \mathrm{~mm}$ и склеены лицевыми сторонами пленок эпоксидной смолой. После механического утоньшения до толщины 20-40 $\mu \mathrm{m}$ с двух сторон образца в направлении параллельном поверхности, проводилось дальнейшее утоньшение ионами аргона $\mathrm{Ar}^{+}$в установке Gatan 691 PIPS (GATAN, CША) при ускоряющем напряжении $5 \mathrm{keV}$ до образования отверстия. Окончательная 


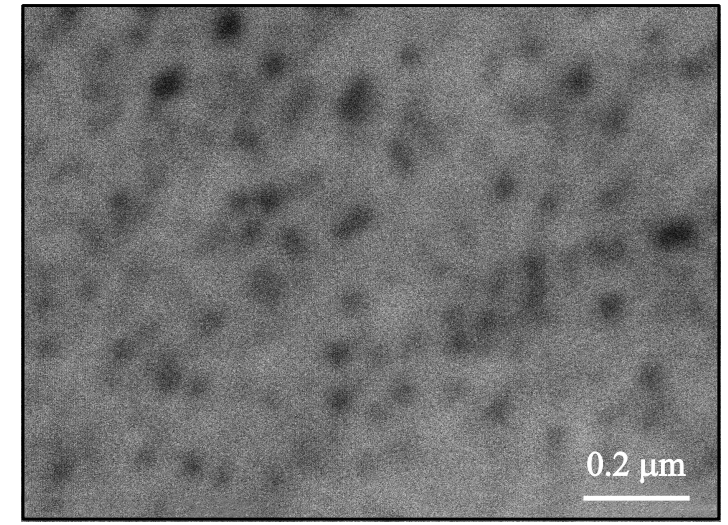

Рис. 1. СЭМ изображение участка поверхности неотожженной пленки GaMnSb.

полировка осуществлялась ионами аргона с энергией $0.1 \mathrm{keV}$. Исследование образцов проводилось в просвечивающем электронном микроскопе TITAN 80-300 (FEI, США) с корректором сферической аберрации зонда в режимах светлого и темного поля. Ускоряющее напряжение составляло $300 \mathrm{kV}$. Обработка изображений была проведена с помощью программного обеспечения Digital Micrograph (Gatan, CША). Расчетная электронограмма построена с помощью программы JEMS.

Измерения температурных зависимостей магнитного момента образцов, охлажденных в нулевом магнитном поле и магнитном поле напряженностью $10 \mathrm{kOe}$, были выполнены с помощью СКВИД-магнитометра (MPMS 5XL Quantum Design).

\section{3. Экспериментальные результаты и их обсуждение}

Изображение поверхности пленки, полученное с помощью СЭМ, показывает наличие включений с латеральными размерами порядка $50 \mathrm{~nm}$ (рис. 1). Элементный состав по данным ЭДРС области пленки, изображенной на рис. 1, был близок к составу исходной мишени $\mathrm{Ga}: \mathrm{Sb}: \mathrm{Mn}=33.2: 46.2$ : 20.6 at.\%. Обнаруживаются так же включения субмикрометровых размеров. С помощью СЗМ было установлено, что такие включения являются ферромагнитными, поскольку при измерениях магнитной топологии пленок (режим МСМ) включения (рис. 2,a) делятся на равные области, одна из которых отталкивает магнитный кантилевер (темная часть включения), а другая - притягивает (светлая часть включения) (рис. 2, b). Нановключения оставались ферромагнитными при нагревании пленок до максимальной рабочей температуры столика микроскопа $T=410 \mathrm{~K}$ (рис. $2, c, d$ ). То есть наблюдаемые нами нановключения с размерами от $50 \mathrm{~nm}$ и выше являются ферромагнитными. Ранее было показано, что наночастицы $\mathrm{MnSb}$ перестают быть ферромагнитными и становятся суперпарамагнитными при снижении их латерального размера до величин порядка $15-30 \mathrm{~nm}[31,32]$.

При исследовании дифракции электронов на неотожженных и отожженных пленках с помощью ПЭМ было установлено, что до термообработки кристаллическая структура пленки является кубической (п. г. $F-43 m)$, а включений - гексагональной (п. г. $P 6_{3} / m m c$ ) (рис. 3). После отжига дифракционная картина от включений


Рис. 2. Изображения двух участков поверхности отожженной пленки GaMnSb, полученные с помощью СЗМ в режимах атомносиловой $(a, c)$ и магнитно-силовой $(b, d)$ микроскопии при температурах $300 \mathrm{~K}(a, b)$ и $410 \mathrm{~K}(c, d)$. 
$a$

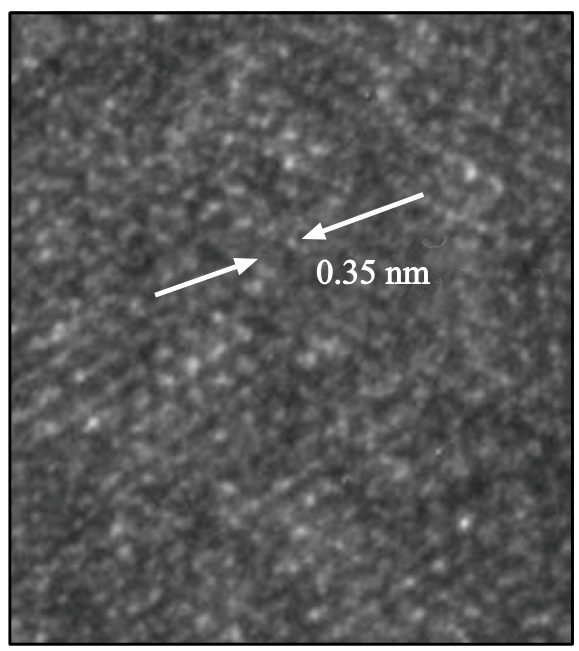

$b$

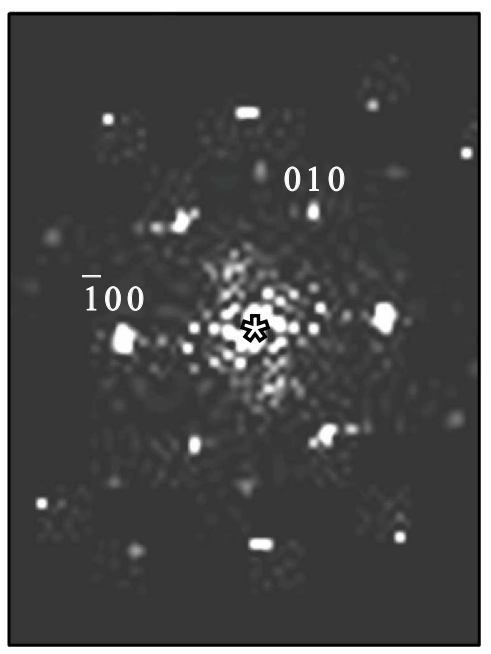

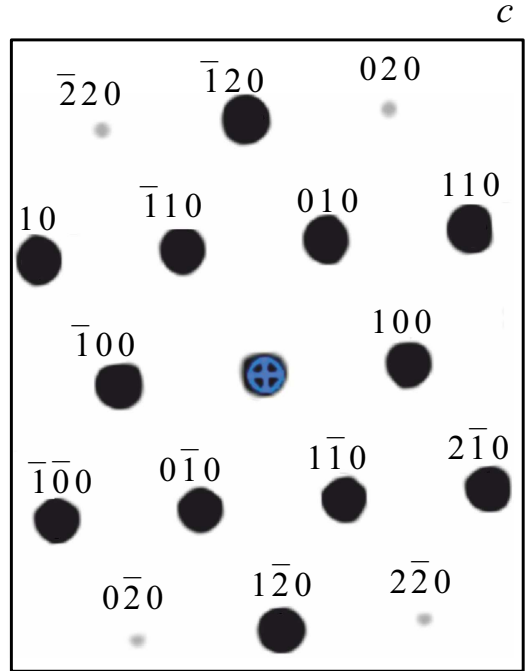

Рис. 3. ПЭМ-изображение высокого разрешения участка неотожженной пленки GaMnSb $(a)$. Двумерный спектр Фурье от этого участка $(b)$ области. Центральный максимум помечен звездочкой. Расчетная электронограмма гексагонального соединения $\mathrm{GaMnSb}$ в проекции [0001] (c).
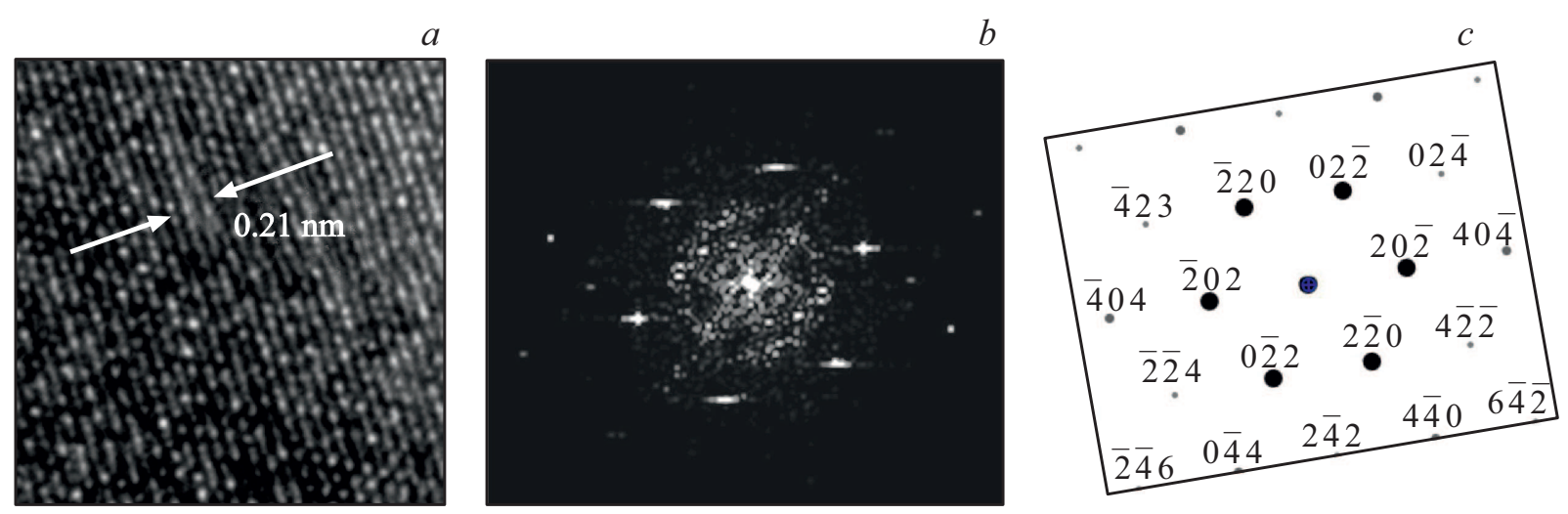

Рис. 4. ПЭМ-изображение высокого разрешения участка неотожженной пленки $\mathrm{GaMnSb}(a)$. Двумерный спектр Фурье от этого участка $(b)$ области. Расчетная электронограмма кубического соединения GaMnSb в проекции [111] $(c)$.

совпадает со структурой полупроводниковой матрицы, то есть кристаллическая структура магнитных нановключений $\mathrm{MnSb}$ так же становится кубической (п. г. $F-43 m$ ) (рис. 4). Ранее по результатам вычислений было показано, что такая кристаллическая структура для $\mathrm{MnSb}$ является нестабильной [33]. Но, в случае ее стабилизации, например, при реализованном недавно эпитаксиальном осаждении тонких слоев $\mathrm{MnSb}$ на подложку GaAs [34], или, как в нашем случае, при формировании $\mathrm{MnSb}$ в виде нановключений в матрице с кубической структурой, $\mathrm{MnSb}$ останется ферромагнитным, а средний магнитный момент на атом марганца увеличится на $10 \%$ (до $4 \mu \mathrm{B}$ ) по сравнению с гексагональной структурой [33].

На рис. 5 приведены температурные зависимости магнитного момента $m(T)$ в магнитном поле $250 \mathrm{Oе}$ для неотожженных (рис. 4, $a$ ) и отожженных (рис. 4, $b$ ) образцов, охлажденных в нулевом магнитном поле (zero- field cooled - ZFC) и магнитном поле напряженностью $10 \mathrm{kOe}$ (field cooled - FC) [28]. Температура, при которой зависимости начинают расходиться, соответствует температуре блокировки нановключений $\mathrm{MnSb} T_{\mathrm{B}}$. Из рис. 5 следует, что температура блокировки в неотожженных образцах составляет $T_{\mathrm{B}}=95 \mathrm{~K}$ (рис. 5, $a$ ), отжиг образцов приводит к значительному возрастанию температуры блокировки до значения $T_{\mathrm{B}}=390 \mathrm{~K}$ (рис. 5,b). Температура блокировки прямо пропорциональна энергией магнитной анизотропии. Таким образом, термообработка пленок $\mathrm{GaMnSb}$ приводит к росту магнитной анизотропии более чем в три раза. Возникает вопрос - сохраняется ли при этом энергетический профиль магнитной анизотропии? Для ответа на этот вопрос ниже будут проанализированы зависимости магнитного момента $m(T)$ для неотожженных и отожженных образцов, охлажденных в нулевом магнитном поле $\left(m_{\mathrm{ZFC}}\right)$ и магнитном поле напряженностью $10 \mathrm{kOe}\left(m_{\mathrm{FC}}\right)$. 

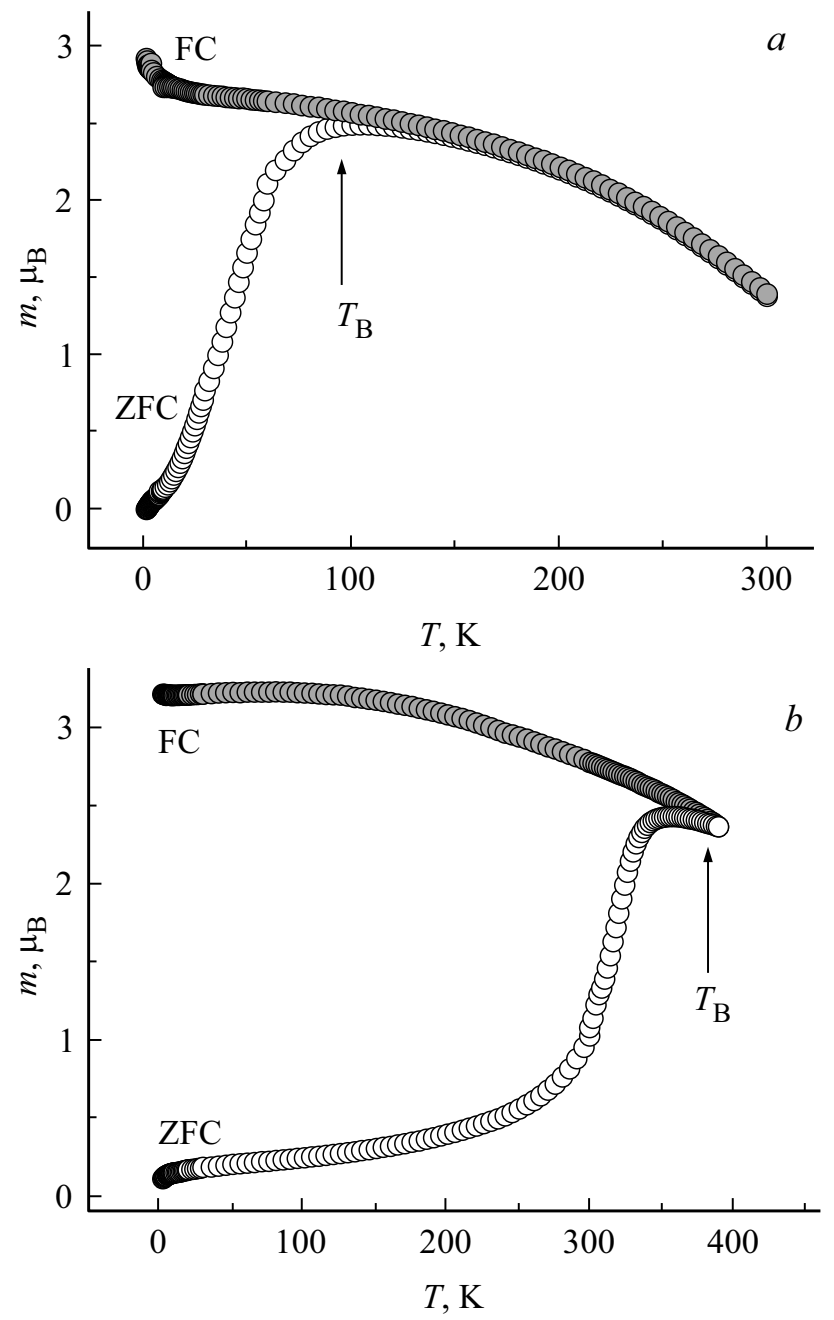

Рис. 5. Температурные зависимости магнитного момента не отожженных $(a)$ и отожженных $(b)$ пленок $\mathrm{GaMnSb}$, охлажденных в нулевом магнитном поле - ZFC (светлые символы) и магнитном поле напряженностью $10 \mathrm{kOe}-\mathrm{FC}$ (темные символы) [28].

Вид зависимостей $m_{\mathrm{ZFC}}$ и $m_{\mathrm{FC}}$ определяется дисперсией магнитной анизотропии, обусловленной распределением нановключений $\mathrm{MnSb}$ по размерам [35]

$$
\begin{aligned}
& m_{\mathrm{ZFC}}=\frac{H M_{S}^{2}}{3 k_{\mathrm{B}} T} \int_{0}^{V_{\lim }} V^{2} \rho(V) d V+\frac{H M_{S}^{2}}{3 K} \int_{V_{\lim }}^{\infty} V \rho(V) d V, \\
& m_{\mathrm{FC}}=\frac{H M_{S}^{2}}{3 k_{\mathrm{B}} T} \int_{0}^{V_{\lim }} V^{2} \rho(V) d V+\frac{H M_{S}^{2}}{3 K} \int_{V_{\lim }}^{\infty} \alpha V \rho(V) d V,
\end{aligned}
$$

где $H$ - напряженность магнитного поля, $M_{S}-$ намагниченность насыщения, $k_{\mathrm{B}}$ - постоянная Больцмана, $T$ - температура, $V$ - объем нановключений, $\rho(V)-$ плотность распределения нановключений по объему, $V_{\lim }$ - объем, выше которого нановключения находятся в блокированном состоянии, $K-$ константа магнитной анизотропии; коэффициент $\alpha$ определяется выражением: $\alpha=0.9283 \ln \left(v_{0} K\langle V\rangle / k_{\mathrm{B}} v_{\mathrm{T}}\right)-3.96, \quad$ коэффициент $\gamma$ определяется выражением: $\quad \gamma=0.9609 \ln \left(v_{0} T_{\max } / \nu_{\mathrm{T}}\right)$ - 1.629 (здесь $v_{0}$ - характерная частота термических флуктуаций, $v_{\mathrm{T}}$ - скорость изменения температуры, $\langle V\rangle$ - средний объем, $T_{\max }$ - температура максимума на зависимости ZFC).

Для удобства анализа экспериментальных данных упростим вид выражений (1) и (2). Для этого запишем выражение для производной по температуре $T$ разности магнитных моментов $\Delta m=m_{\mathrm{FC}}-m_{\mathrm{ZFC}}$, предварительно сделав в интеграле замену переменных $V=\gamma k_{\mathrm{B}} T / K$

$$
\frac{d(\Delta m)}{d T}=\frac{H M_{S}^{2}}{3 K}(\alpha-1)\left(\frac{\gamma k_{\mathrm{B}}}{K}\right)^{2} T \rho\left(\frac{\Gamma k_{\mathrm{B}} T}{K}\right) .
$$

На рис. 5 представлены температурные зависимости производной $d(\Delta m) / d T$ для неотожженных и отожженных образцов. Немонотонная зависимость $d(\Delta m) / d T$ отражает распределение нановключений $\mathrm{MnSb}$ по объему или, что тоже самое, по температуре блокировки $[35,36]$. Приведенные на рис. 6 кривые, воспроизводят вид зависимостей $\rho\left(E_{a}\right)$ (здесь $E_{a}=K V-$ энергия магнитной анизотропии), а, следовательно, и энергетический профиль магнитной анизотропии.

Плотность распределения $\rho$ нановключений $\mathrm{MnSb}$ по $E_{a}$ (по $V$ или $T_{\mathrm{B}}$ ) в неотожженных образцах, как видно на рис. 6 , является унимодальным с правосторонней асимметрией (правый „хвост“ значительно длиннее левого). Такая форма характерна для логнормальной функции

$$
\rho(V)=\frac{1}{V \sigma \sqrt{2 \pi}} \exp \left(-\frac{1}{2}\left[\frac{\ln \frac{V}{V_{m}}}{\sigma}\right]^{2}\right),
$$

где $\sigma-$ дисперсия, $V_{m}-$ медианный объем $\left(V_{m}=8\langle V\rangle \exp \left(-9 \sigma^{2} / 2\right)\right)$. Зависимости производной

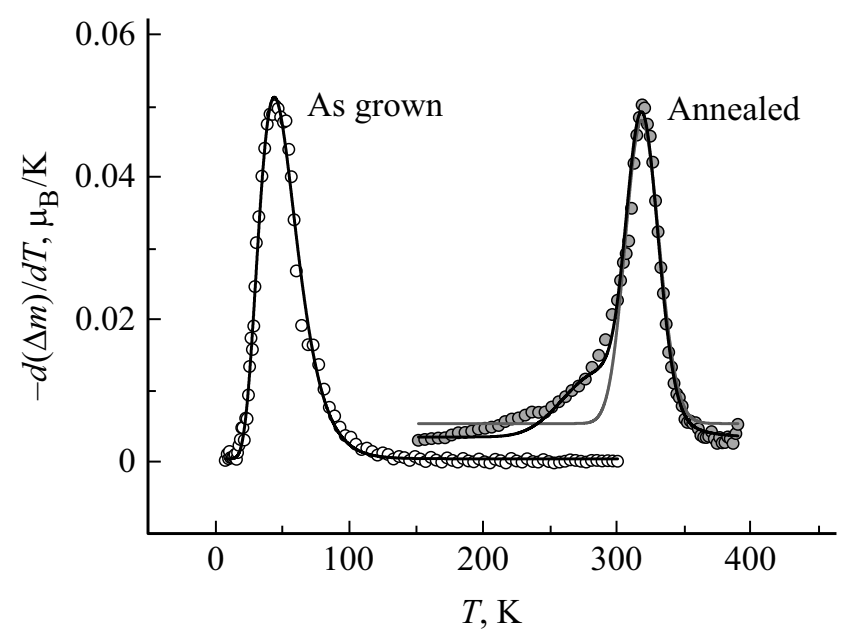

Рис. 6. Температурные зависимости производной $d(\Delta m) / d T$ для неотожженного (светлые символы) и отожженного образца (темные символы). Сплошными линиями показаны аппроксимации. 
$d(\Delta m) / d T$ для неотожженных образцов аппроксимированы выражением (3) с функцией распределения, задаваемой формулой (4) (рис. 6). Коэффициент детерминации $R^{2}=0.99$. Из аппроксимации были определены константа $K=0.9 \cdot 10^{4} \mathrm{erg} / \mathrm{cm}^{3}$ и дисперсия магнитной анизотропии $\sigma=0.7$.

Плотность распределения $\rho$ нановключений $\mathrm{MnSb}$ по $E_{a}$ (по $V$ или $T_{\mathrm{B}}$ ) в отожженных образцах, как видно на рис. 6, имеет правостороннюю асимметрию (левый „хвост“ значительно длиннее правого), что, вообще говоря, нехарактерно для логнормальной функции. Аппроксимация зависимости производной $d(\Delta m) / d T$ выражением (3) с функцией распределения, задаваемой формулой (4), на рис. 6 показана линией серого цвета. Коэффициент детерминации $R^{2}=0.95$ ниже соответствующего значения для аппроксимации соответствующей зависимости в неотожженных образцах. Из аппроксимации были определены $K=3.2 \cdot 10^{4} \mathrm{erg} / \mathrm{cm}^{3}$ и $\sigma=1.5$. Таким образом, термообработка пленок $\mathrm{GaMnSb}$ приводит к росту $K$ более чем в три раза и двукратному увеличению дисперсии магнитной анизотропии. Увеличение константы магнитной анизотропии в результате термообработки можно объяснить переходом кристаллической структуры магнитных нановключений $\mathrm{MnSb}$ из гексагональной (п. г. $\left.P 6_{3} / m m c\right)$ в кубическую (п. г. $\left.F-43 m\right)$. Связь увеличения дисперсии магнитной анизотропии и структурного фазового перехода неочевидна. Возможно, какую-то роль может играть возникающее рассогласование решеток между $\mathrm{MnSb}$ и $\mathrm{GaSb}$. Если оно заметное, то увеличение $\sigma$ можно было бы связать с ростом напряжений в гранулах (кристаллического потенциала). К сожалению, однозначно определить возможный рост или падение напряжений кристаллической решетки в гранулах, возникающие в результате фазового перехода, методами электронной микроскопии не представляется возможным из-за поликристаллического характера пленок. Прилегающие гранулы сопрягаются различными гранями, ориентационные соотношения между гранулами значительно различаются, причем границы раздела не плоские. Все это создает возможности снятия напряжений в виде дислокаций несоответствия различного типа или возникновения атомарных ступеней, также уменьшающих напряжение кристаллических решеток [30]. Нельзя исключать, что увеличение магнитной анизотропии и ее дисперсии в результате термообработки обусловлено увеличением среднего объема нановключений, вызванное диффузионно-контролируемой агрегацией акцепторной примеси марганца в $\mathrm{MnSb}$. Кроме того, система $\mathrm{MnSb}$ образует широкий ряд твердых растворов $\mathrm{Mn}_{1+x} \mathrm{Sb}$ и их магнитные свойства существенно зависят от состава. Так, температура Кюри $\mathrm{Mn}_{1+x} \mathrm{Sb}$ уменьшается от $580 \mathrm{~K}$ до $510 \mathrm{~K}$ [37], а константа магнитной анизотропии первого порядка изменяет свой знак [38] при увеличении $x$ от нуля до 0.1. На возможное изменение состава включений и самой пленки в сторону стехиометрического указывают приведенные в работе [28] результаты исследования комбинационного рассеяния света, что, в свою очередь, также может приводить к изменению магнитной анизотропии. Подобным образом, например, объясняется увеличение эффективного магнитного момента пленок GaMnSb после отжига [24]. Скорее всего, в образцах при отжиге протекают все описанные выше явления одновременно. Присутствие нескольких факторов, влияющих на исследуемую систему, может приводить к тому, что выборка в отожженных образцах не является однородной и наблюдения порождены двумя или более „наложенными“распределениями, то есть распределение $\rho$ нановключений $\mathrm{MnSb}$ по $E_{a}$ (по $V$ или $T_{\mathrm{B}}$ ) в отожженных образцах может быть мультимодальным. Линией черного цвета на рис. 5 показана аппроксимация зависимости производной $d(\Delta m) / d T$ выражением (3) с двумя функциями распределения, задаваемыми формулой (4). Это эквивалентно предположению, что выборка происходит из двух разных

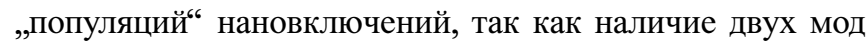
в одной популяции маловероятное явление. Коэффициент детерминации $R^{2}=0.99$ выше, чем в случае унимодального распределения. Из аппроксимации были определены значения $K=2.9 \cdot 10^{4} \mathrm{erg} / \mathrm{cm}^{3}$ для одной „,Популяции“нановключений и $K=3.2 \cdot 10^{4} \mathrm{erg} / \mathrm{cm}^{3}$ для другой, значения $\sigma=1.07$ для обеих „популяции“ были близки.

\section{4. Заключение}

С помощью СКВИД-магнитометра измерены температурные зависимости магнитного момента $m(T)$ для неотожженных и отожженных образцов тонких пленок $\mathrm{GaMnSb}$, охлажденных в нулевом магнитном поле и магнитном поле напряженностью $10 \mathrm{kOe}$. Анализ экспериментальных зависимостей $m(T)$ показал, что термообработка пленок $\mathrm{GaMnSb}$ приводит к росту магнитной анизотропии (значение константы $K$ увеличивается более чем в три раза) и двукратному увеличению дисперсии магнитной анизотропии. При этом распределение по энергии магнитной анизотропии нановключений $\mathrm{MnSb}$, внедренных в тонкие пленки, из унимодального становится мультимодальным. Это может означать что, в образцах при отжиге протекают несколько термоактивированных процессов, влияющих на исследуемую систему и приводящих к тому, что в отожженных тонких пленках присутствуют несколько „популяций ${ }^{6}$ нановключений. Помимо основного процесса - переход кристаллической структуры магнитных нановключений $\mathrm{MnSb}$ из гексагональной (п. г. $P 6_{3} / m m c$ ) в кубическую (п.г. $F-43 m)$, в образце при отжиге могут возникать: рассогласование кристаллических решеток между $\mathrm{MnSb}$ и $\mathrm{GaSb}$; увеличение среднего объема нановключений $\mathrm{MnSb}$, вызванное диффузионно-контролируемой агрегацией акцепторной примеси марганца; изменение стехиометрии нановключений $\mathrm{MnSb}$ и др.

А.И. Дмитриев признателен А.Д. Таланцеву за помощь в исследованиях на СКВИД-магнитометре. 


\section{Список литературы}

[1] F. Meier, B.P. Zakharchenya. Optical Orientation. Modern Problems in Condensed Matter Science / Ed. V.M. Agronovich, A.A. Maradudin. Elsevier, Amsterdam, North Holland Publishing Co., V. 8 (1984).

[2] G.A. Prinz. Science 250, 1092 (1990).

[3] T. Dietl, H. Ohno, F. Matsukura, J. Cibert, D. Ferrand. Science 287, 1019 (2000)

[4] В.А. Иванов, Т.Г. Аминов, В.М. Новоторцев, В.Т. Калинников. Спинтроника и спинтронные материалы. Изв. АН Сер. хим. 11, 2255 (2004).

[5] T. Jungwirth, J. Sinova, J. Mašek, J. Kučera, A.H. MacDonald. Rev. Mod. Phys. 78, 809 (2006).

[6] S. Kuroda, N. Nishizawa, K. Takita, M. Mitome, Y. Bando, K. Osuch, T. Dietl. Nature Mater. 6, 440 (2007).

[7] T. Dietl, H. Ohno. Rev. Mod. Phys. 86, 187 (2014)

[8] K. Sato, L. Bergqvist, J. KudrnovskT́, P.H. Dederichs, O. Eriksson, I. Turek, B. Sanyal, G. Bouzerar, H. KatayamaYoshida, V.A. Dinh, T. Fukushima, H. Kizaki, R. Zeller. Rev. Mod. Phys. 82, 1633 (2010).

[9] R.B. Morgunov, A.I. Dmitriev, O.L. Kazakova. Physic. Rev. B 80, 085205 (2009).

[10] А.И. Дмитриев, Р.Б. Моргунов, О.Л. Казакова, Й. Танимото. ЖЭТФ 135, 1134 (2009).

[11] L.N. Oveshnikov, E.I. Nekhaeva, A.V. Kochura, A.B. Davydov, M.A. Shakhov, S.F. Marenkin, O.A. Novodvorskii, A.P. Kuzmenko, A.L. Vasiliev, B.A. Aronzon, E. Lahderanta. Beilstein J. Nanotechnol. 9, 2457 (2018).

[12] J.D. Boeck, R. Oesterholt, A.V. Esch, H. Bender, C. Bruynseraede. Appl. Phys. Lett., 68, 2744 (1996).

[13] A. Bonanni, A. Navarro-Quezada, T. Li, M. Wegscheider, Z. Matěj, V. Holý, R.T. Lechner, G. Bauer, M. Rovezzi, F. D'Acapito, M. Kiecana, M. Sawicki, T. Dietl. Phys. Rev. Lett. 101, 135502 (2008).

[14] F. Matsukura, E. Abe, H. Ohno. J. Appl. Phys. 87, 6442 (2000).

[15] F. Matsukura, E. Abe, Y. Ohno, H. Ohno. Appl. Surf. Sci. 159-160, 265 (2000).

[16] A.V. Kochura, B.A. Aronzon, K.G. Lisunov, A.V. Lashkul, A.A. Sidorenko, R. De Renzi, S.F. Marenkin, M. Alam, A.P. Kuzmenko, E. Lahderanta. J. Appl. Phys. 113, 083905 (2013).

[17] H. Akinaga, S. Miyanishi, K. Tanaka, W. Van Roy, K. Onodera. Appl. Phys. Lett. 76, 97 (2000).

[18] H. Shimizu, M. Tanaka. J. Appl. Phys. 89, 7281 (2001).

[19] Sh.U. Yuldashev, Y. Shon, Y.H. Kwon, D.J. Fu, D.Y. Kim, H.J. Kim, T.W. Kang, X. Fan. J. Appl. Phys. 90, 3004 (2001).

[20] Р.Б. Моргунов, М. Фарле, О.Л. Казакова. ЖЭТФ 134, 141 (2008).

[21] R. Morgunov, M. Farle, M. Passacantando, L. Ottaviano, O. Kazakova. Phys. Rev. B 78, 045206 (2008).

[22] P.N. Hai, S. Ohya, M. Tanaka, S.E. Barnes, S. Maekawa. Nature 458, 489 (2009).

[23] В.В. Рыльков, Б.А. Аронзон, Ю.А. Данилов, Ю.Н. Дроздов, В.П. Лесников, К.И. Маслаков, В.В. Подольский. ЖЭТФ 127, 838 (2005).

[24] А.Д. Таланцев, О.В. Коплак, Р.Б. Моргунов. ФТТ 57, 307 (2015).
[25] О.В. Коплак, А.А. Поляков, А.Б. Давыдов, Р.Б. Моргунов, А.Д. Таланцев, А.В. Кочура, И.В. Федорченко, О.А. Новодворский, Л.С. Паршина, О.Д. Храмова, А.В. Шорохова, Б.А. Аронзон. ЖЭТФ 147, 1170 (2015).

[26] A.I. Dmitriev, A.D. Talantsev, O.V. Koplak, R. Morgunov. J. Appl. Phys. 119, 073905 (2016).

[27] А.И. Дмитриев, А.А. Филатов. ФТТ 59, 1712 (2017).

[28] А.И. Дмитриев, А.В. Кочура, А.П. Кузьменко, Л.С. Паршина, О.А. Новодворский, О.Д. Храмова, Е.П. Кочура, А.Л. Васильев, Б.А. Аронзон. ЖЭТФ 154, 613 (2018).

[29] С.Ф. Маренкин, О.А. Новодворский, А.В. Шорохова, А.Б. Давыдов, Б.А. Аронзон, А.В. Кочура, И.В. Федорченко, О.Д. Храмова, А.В. Тимофеев. Неорган. материалы 50 973 (2014).

[30] A.A. Lotin, O.A. Novodvorsky, L.S. Parshina, E.V. Khaydukov, D.A. Zuev, O.D. Khramova, V.Ya. Panchenko. Appl. Phys. B 104, 565 (2011).

[31] H. Zhang, S.S. Kushvaha, S. Chen, X. Gao, D. Qi, A.T.S. Wee, X.-S. Wang. J. Appl. Phys. 90, 202503 (2007).

[32] M.A. Hettiarachchi, E. Abdelhamid, B. Nadgorny, S.L. Brock. J. Mater. Chem. C 4, 6790 (2016).

[33] J.D. Aldous, C.W. Burrows, A.M. Sanchez, R. Beanland, I. Maskery, M.K. Breadley, M.D. Dias, J.B. Staunton, G.R. Bell. Phys. Rev. B 85, 060403 (2012).

[34] J.-Ch. Zheng, J.W. Davenport. Phys. Rew. B. 69, 144415 (2004).

[35] F. Tournus, A. Tamion. J. Magn. Magn. Mater. 323, 1118 (2011).

[36] I.J. Bruvera, P.M. Zelis, M.P. Calatayud, G.F. Goya, F.H. Sanchez. J. Appl. Phys. 118, 184304 (2015).

[37] V. Seshi Bai, K.V.S. Rama Rao. J. Appl. Phys. 55, 2167 (1984).

[38] T. Okita, Y. Makino. J. Phys. Soc. Jpn. 25, 120 (1968).

Редактор К.В. Емцев 